\title{
Períodos de interferência das plantas daninhas em algodoeiro de fibra colorida 'BRS Safira'1
}

\author{
Weeds interference periods in naturally colored cotton 'BRS Safira'
}

\author{
Gleibson Dionízio Cardoso ${ }^{2 *}$, Pedro Luís da Costa Aguiar Alves ${ }^{3}$, Napoleão Esberard de Macêdo Beltrão ${ }^{4}$ e \\ Leandro Silva do Vale ${ }^{5}$
}

\begin{abstract}
Resumo - Objetivou-se com esse trabalho, identificar os períodos de interferência das plantas daninhas no algodoeiro de fibra colorida (BRS Safira), bem como avaliar a comunidade infestante nesta cultura. O experimento foi realizado no município de Missão Velha, CE, região do Cariri, na safra 2007/2008. Utilizou-se o delineamento experimental em blocos ao acaso, com quatro repetições, em esquema fatorial 2 x 5 , sendo os fatores: modalidades de competição (com e sem competição de plantas daninhas) e período de interferência das plantas daninhas. A comunidade infestante foi avaliada por meio de dois índices fitossociológicos (Dominância relativa e Importância relativa). Os períodos iniciais de controle ou de convivência após a emergência da cultura foram 0-20;0-40;0-60;0-80 dias após a emergência (DAE) e 0-colheita. Os períodos de interferência foram determinados considerando-se perdas na produtividade de 2; 5 e 10\%; realizando-se análise de regressão pelo modelo sigmoidal de Boltzman, utilizando-se os dados de produtividade para cada modalidade de competição. Dentre as 21 espécies observadas na comunidade infestante, destacaram-se: Richardia grandiflora, Amaranthus deflexus, Eleusine indica, Merremia aegyptia, Eragrotis pilosa, Cenchrus echinatus e Waltheria indica. Os períodos críticos anteriores à interferência foram, respectivamente, $8 ; 14$ e 20 DAE, para perdas na produtividade de $2 ; 5$ e $10 \%$; e os períodos críticos de prevenção a interferências, foram, respectivamente, 100; 82 e 60 dias.
\end{abstract}

Palavras-chave - Gossypium hirsutum L. Raça latifolium. Fibra colorida. Ervas daninhas. Competição.

\begin{abstract}
This study aimed to determine the late-season presence of weeds in reddish brown cotton (cultivar BRS Safira) and the critical times for removing weeds. The experiment was carried out in the area of Embrapa in Missão Velha-CE, Brazil, located at $7^{\circ} 42^{\prime} 07^{\prime}$ ' S latitude and 39'24'18', WGr. longitude, during the 2007/2008 season. The treatments consisted of two control groups: weed-free crop during the initial period after crop emergency, and crop kept with weeds during initial period after plant emergency. Both consisted, $0 ; 20 ; 40 ; 60 ; 80$ e 120 days after crop emergency (DAE), the weed community was evaluated by two phytosociological indices (relative dominance and relative importance). Regression analysis was performed as the model of sigmoidal Boltzman, using data from productivity separately within each type of competition, to identify the critical periods of competition, considering 2; 5 and 10\% reduction in yield. The community of weeds was composed by 21 species, standing out among them: Richardia grandiflora, Amaranthus deflexus, Eleusine indica, Merremia aegyptia, Eragrotis pilosa, Cenchrus echinatus and Waltheria indica. Considering 2; 5 and 10\% reduction in yield fiber as acceptable, the critical period before weed interference were, respectively, 8; 14 and 20 DAE. The critical period of weed interference, for those same levels of losses, were respectively, 100; 82 and 60 days.
\end{abstract}

Key words - Gossypium hirsutum L. Race latifolium. Naturally colored cottons. Competition.

\footnotetext{
* Autor para correspondência

${ }^{1}$ Recebido para publicação em 29/07/2009; aprovado em 20/07/2010

Parte da Tese do primeiro autor apresentada ao Programa de Pós-Graduação em Produção Vegetal da FCAV/UNESP

${ }^{2}$ Assistente de Pesquisa da Embrapa Algodão, Campina Grande-PB, Brasil, gleibson75@hotmail.com

${ }_{3}^{3}$ Departamento de Biologia Aplicada a Agricultura, FCAV/UNESP, Jaboticabal-SP, Brasil, plalves@fcav.unesp.br

${ }^{4}$ Pesquisador da Embrapa Algodão, Campina Grande-PB, Brasil, nbeltrao@cnpa.embrapa.br

${ }^{5}$ Programa de Pós-Graduação em Agronomia, UFPB/CCA, Areia-PB, Brasil, leandroferligran@hotmail.com
} 


\section{Introdução}

Há mais de 4.500 anos os Incas e Astecas já utilizavam o algodão colorido, bem como outros povos antigos das Américas, Ásia, África e Austrália. Neste último país, 50 espécies silvestres de algodão foram identificadas, sendo mais de dez espécies com fibras coloridas. Por muito tempo esses algodões foram descartados pela indústria têxtil mundial e, até mesmo, foi proibida sua exploração em vários países, por serem considerados contaminantes dos algodões de tonalidade branca convencional (BELTRÃO; CARVALHO, 2004).

A cultura do algodão colorido tem grande potencial econômico, tanto como fixador de mão-de-obra e gerador de empregos, como também fonte de matéria-prima para a indústria, e com grande apelo ambiental, uma vez, que elimina a fase de tingimento na indústria, a qual tem lançado grande quantidade de resíduos no ambiente. Entretanto, o cultivo do algodão colorido é recente no país, e por ter um mercado ainda pouco expressivo, são quase inexistentes na literatura informações recentes sobre a interferência das plantas daninhas, principalmente estudos envolvendo a definição do período crítico de interferência das plantas daninhas nesta cultura.

A maioria dos estudos sobre competição entre plantas daninhas e culturas tem como metas definir períodos críticos de interferência, visando a máxima capacidade produtiva da cultura (MELHORANÇA; BELTRÃO, 2001). O conhecimento da época e dos períodos de convivência entre a cultura e as plantas daninhas é de grande importância, pois a extensão do período de convivência que afeta a cultura pode ser alterada pelos métodos de controle empregados pelo homem (PITELLI; PITELLI, 2008).

Para Melhorança e Beltrão (2001), o período crítico de prevenção à interferência das plantas daninhas no algodoeiro é de 15 a 56 dias após a emergência das plântulas. Já Salgado et al. (2002), trabalhando com a cultivar Delta Opal, observaram um período anterior à interferência de 8 dias após a emergência, considerando uma redução aceitável de $5 \%$ na produtividade, com o período crítico de prevenção à interferência no intervalo de
8 a 66 dias, e o período total de prevenção a interferência de 66 dias após a emergência.

Porém, as informações na literatura científica com relação aos períodos de interferências das plantas daninhas na cultura do algodoeiro de fibra colorida são superficiais, principalmente, nas cultivares recém lançadas (BRS Verde, BRS Rubi e BRS Safira) amplamente adaptadas para o Nordeste, podendo também ser plantadas em regiões onde se planta o algodão convencional.

Considerando a importância da cultura em questão e a necessidade de informações sobre matocompetição, o presente trabalho tem por objetivos identificar os diferentes períodos de interferência das plantas daninhas no algodoeiro de fibra naturalmente colorida, BRS Safira, bem como avaliar a comunidade infestante, por meio de dois índices fitossociológicos (Dominância relativa e Importância relativa) na região do Cariri em Missão Velha, CE.

\section{Material e métodos}

O experimento foi realizado na área experimental do Centro Nacional de Pesquisa do Algodão/ EMBRAPA em Missão Velha, CE, região do Cariri, a $7^{\circ} 42^{\prime} 07^{\prime \prime}$ de latitude e $39^{\circ} 24^{\prime} 18^{\prime \prime}$ ' de longitude, altitude de $360 \mathrm{~m}$, na safra 2007/2008 em solo de textura areno-argilosa e classificado como Neossolo Regolítico, cujas características químicas encontramse na Tabela 1. O clima da região é classificado como tropical quente semi-árido brando, com precipitação pluvial média anual de $987,3 \mathrm{~mm}$. Durante a condução do experimento a precipitação pluvial foi de $322 \mathrm{~mm}$ e com temperatura média de $26,4^{\circ} \mathrm{C}$. Utilizou-se a cultivar do algodoeiro de fibra naturalmente colorida, BRS Safira de ciclo curto (140 a 150 dias), no espaçamento de $1,00 \times 0,20 \mathrm{~m}$ entre linhas e plantas, respectivamente. A unidade experimental constou de quatro fileiras de $6,0 \mathrm{~m}$ de comprimento, para coleta dos dados de produção e de levantamento da comunidade infestante. Considerou-se como área útil, as duas fileiras centrais, eliminando-se $0,5 \mathrm{~m}$ das extremidades como bordadura.

Tabela 1 - Resultados da análise química do solo da área experimental. Missão Velha, 2007

\begin{tabular}{|c|c|c|c|c|c|c|c|c|}
\hline \multicolumn{9}{|c|}{ Análise Química } \\
\hline $\mathrm{pH}$ & $\mathrm{Ca}^{+2}$ & $\mathrm{Mg}^{+2}$ & $\mathrm{Na}^{+}$ & $\mathrm{K}^{+}$ & $\mathrm{H}+\mathrm{Al}$ & $\mathrm{P}$ & M.O. & $\mathrm{V}$ \\
\hline$(1: 25)$ & --------- & -------- & $\mathrm{ol} \mathrm{m}^{-3}$ & - & --------- & $\mathrm{mg} \mathrm{dm}^{-3}$ & $\mathrm{~g} \mathrm{~kg}^{-1}$ & $\%$ \\
\hline 6,0 & 23,2 & 12,2 & 0,7 & 3,4 & 12,4 & 15,9 & 7,6 & 76 \\
\hline
\end{tabular}

Fonte: Laboratório de Solos e Nutrição de Plantas do CNPA/EMBRAPA, Campina Grande, PB 
Utilizou-se o delineamento experimental emblocos ao acaso, com quatro repetições, sendo os tratamentos dispostos em esquema fatorial 2 x 5 , sendo os fatores: modalidades de competição (com e sem competição de plantas daninhas) e período de interferência das plantas daninhas. Os tratamentos implantados após a emergência das plântulas de algodão constaram de dois grupos. No primeiro, a cultura, a partir de sua emergência que ocorreu aos 7 dias, permaneceu livre da competição das plantas daninhas durante determinados períodos: $0-20 ; 0-40 ; 0-60 ; 0-80$ dias, e até a colheita que foi aos 120 dias. Após esses períodos, as plantas daninhas que emergiram nas parcelas cresceram livremente. No segundo grupo, procedeu-se ao contrário: a cultura, a partir de sua emergência, permaneceu em competição com a comunidade infestante durante os períodos mencionados para o primeiro grupo de tratamentos.

A semeadura do algodoeiro foi realizada em 08/03/2007 após o preparado do solo com duas arações e duas gradagens niveladoras e os tratos culturais realizados de acordo com as recomendações de Beltrão (2004). Para o controle das pragas utilizouse inseticidas, levando-se em consideração o Manejo Integrado de Pragas (MIP), de acordo com cada nível de controle da praga.

As amostragens das plantas daninhas foram realizadas ao final de cada período de convivência ou início do controle, antes que se procedesse ao controle manual. Nestas amostragens foram utilizados quadros vazados de ferro com $0,5 \mathrm{~m}$ de lado e área interna de $0,25 \mathrm{~m}^{2}$, que foram lançados ao acaso quatro vezes na área útil das parcelas. As plantas contidas na área amostral foram cortadas rente ao solo, separadas e contadas por espécie de forma a se obter a densidade e a massa de matéria seca específica. A matéria seca da parte aérea das plantas daninhas foi obtida em estufa com ventilação forçada de ar a $70^{\circ} \mathrm{C}$, até peso constante e posteriormente pesadas. De posse desses dados, foi calculado o Índice de importância relativa (IR) que se refere à representação do valor da importância de uma espécie em relação à somatória dos valores de importância de todas as populações da comunidade; e a Dominância Relativa (Do.R), que representa a relação entre o acúmulo de matéria seca total da população e da comunidade infestante, de cada espécie dentro da comunidade infestante, conforme metodologia proposta por Mueller-Dombois e Ellemberg, (1974).

A colheita do algodão em caroço foi realizada manualmente, sendo iniciada no dia 12/07/2007, quando $70 \%$ dos capulhos estavam abertos, repetindo a colheita quando necessária. A produtividade foi expressa em massa de algodão em caroço.
Para determinação dos períodos de interferência, foi realizada análise de regressão do modelo sigmoidal de Boltzman, utilizando os dados de produtividade separadamente dentro de cada modalidade de competição, tolerando perdas máximas de produção de $2 ; 5$ e $10 \%$ em relação à obtida nas parcelas mantidas no limpo durante todo ciclo (KNEZEVIC et al., 2002; KUVA et al., 2000).

\section{Resultados e discussão}

A comunidade de plantas infestante na cultura do algodão foi composta por 21 espécies, sendo 71,43\% Magnoliopsidas e 28,57\% das Liliopsidas. Dentre as Magnoliopsidas destacaram-se Richardia grandiflora; Amaranthus deflexus; Merremia aegyptia; Waltheria indica, Sida acuta; Turnera indica; Crotalaria retusa; e em menor importância, Solanum ambrosiacum e Phyllanthus niruri (TAB. 2). Com relação ao grupo das Liliopsidas, destacaram-se as espécies Eleusine indica, Eragrotis pilosa, Cenchrus echinatus, Cynodon dactylon, Dactyloctenium aegyptium e Cyperus compressus. No nordeste do Brasil, as espécies que causam maiores problemas são: Richardia grandiflora, Eragrotis pilosa, Turnera indica, Crotalaria retusa, Sida acuta e Solanum ambrosiacum, enquanto que as demais observadas são freqüentes nesta cultura em outras regiões do País (BELTRÃO, 2004; FREITAS et al., 2002; FREITAS et al., 2006). No que diz respeito à competição imposta por essa comunidade à cultura, verificou-se redução na produtividade de até $91,93 \%$ quando se deixou as plantas daninhas competir durante todo ciclo da cultura.

Quando se avaliou a dominância relativa (Do.R) (FIG. 1), verifica-se que no início do ciclo da cultura (aos 20 DAE), o capim-pé-de-galinha (ELEIN), a jetirana (IPOPE), quebra-panela (RCHGR) e o caruru (AMADE) já estavam estabelecidos. Conforme salientam Morgan et al. (2001) e Bukun (2004) plantas daninhas que desenvolvem-se no início das culturas com crescimento lento, como no caso do algodoeiro, influenciam negativamente, presumivelmente pela redução da fotossíntese da cultura. Verificou-se acúmulo de matéria seca durante todo o ciclo para o capimpé-de-galinha (ELEIN), permanecendo constante para o quebra-panela atingindo valores de $25,60 \%$ (aos 60 DAE) e $33,43 \%$ (80 DAE), já a jetirana teve o máximo de acúmulo de matéria seca aos 60 dias após a emergência com 31,62\% de toda comunidade. Essa queda na dominância relativa do capim-pé-de-galinha (ELEIN), também foi observada em outras Liliopsidas, e coincide com o aumento da dominância relativa das Magnoliopsidas, especialmente a Richardia grandiflora e Merremia aegyptia, mostrando ampla distribuição de espécies durante todo o ciclo da cultura. 
Tabela 2 - Comunidade infestante da cultura do algodão de fibra naturalmente colorida (BRS Safira) no decorrer do período experimental, com respectivos códigos internacionais. Missão Velha-CE, 2007

\begin{tabular}{|c|c|c|c|}
\hline Família & Espécie & COD.* & Nome popular \\
\hline \multicolumn{4}{|c|}{ Magnoliopsida } \\
\hline Rubiaceae & Richardia grandiflora (Cham. \& Schltdl.) Steud. & RCHGR & quebra-panela \\
\hline Amaranthaceae & Amaranthus deflexus $\mathrm{L}$. & AMADE & caruru \\
\hline \multirow{2}{*}{ Convolvulaceae } & Merremia aegyptia (L.) Urban & IPOPE & jetirana \\
\hline & Ipomoea asarifolia (Desr.) Roem. \& Schult. & IPOAS & salsa \\
\hline \multirow{2}{*}{ Malvaceae } & Waltheria indica $\mathrm{L}$. & WALAM & malva branca \\
\hline & Sida acuta Burm F. & SIDAC & relógio \\
\hline Turneraceae & Turnera indica $\mathrm{L}$. & TURIN & chanana \\
\hline \multirow{3}{*}{ Fabaceae } & Crotalaria retusa $\mathrm{L}$. & CVTRE & chucalho-de-cobra \\
\hline & Centrosema virginianum (L.) Benth. & -------- & maria-sem-vergonha \\
\hline & Macroptilium lathyroides (L.) Urb. & -------- & feijão-de-rola \\
\hline Nyctaginaceae & Boerhaavia diffusa $\mathrm{L}$. & BOEDI & pega-pinto \\
\hline Portulacaceae & Portulaca pilos $\mathrm{L}$. & PORPI & beldroega \\
\hline Solanaceae & Solanum ambrosiacum Vell. & SOLAB & melancia de praia \\
\hline \multirow{2}{*}{ Euphorbiaceae } & Chamaesyce hyssopifolia (L.) Small & EPHHS & erva-de-santa-luzia \\
\hline & Phyllanthus niruri L. & PYLNI & quebra pedra \\
\hline \multicolumn{4}{|c|}{ Liliopsida } \\
\hline \multirow{5}{*}{ Poaceae } & Eleusine indica (L.) Gaert & ELEIN & pé de galinha \\
\hline & Eragrotis pilosa (L.) Beauv. & ERAPI & capim-mimoso \\
\hline & Cenchrus echinatus $\mathrm{L}$. & CCHEC & capim-arrapicho \\
\hline & Cynodon dactylon (L.) Pers. & CYNDA & grama-seda \\
\hline & Dactyloctenium aegyptium (L.) Willd. & DTTAE & mão-de-sapo \\
\hline Cyperaceae & Cyperus compressus $\mathrm{L}$. & CYPCP & barba de bode \\
\hline
\end{tabular}

* códigos internacionais para os nomes científicos das espécies

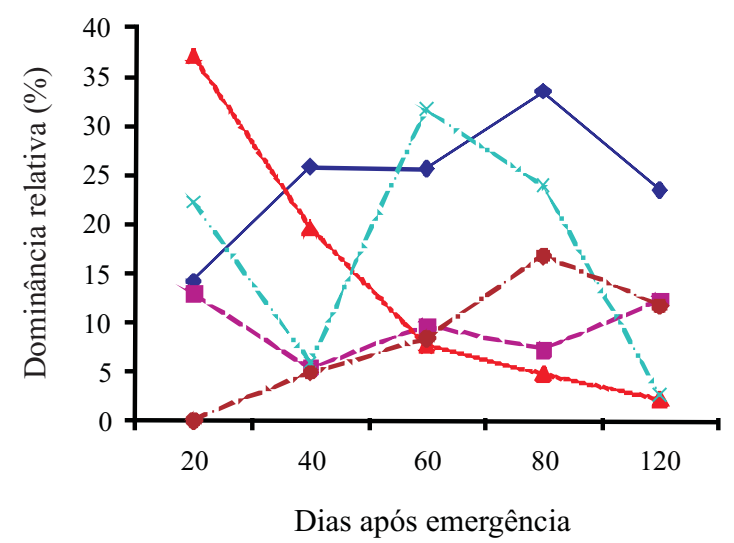

$\longrightarrow$ RCHGR $-\bullet-\cdot$ AMAVI $\longrightarrow$ ELEIN $-x-r$ IPOPE $-r-$ CCHEC

Figura 1 - Dominância relativa (Do.R) das principais plantas daninhas presentes na área experimental em função do número de dias após emergência (DAE) do algodão de fibra naturalmente colorida. Missão Velha-CE 2007
Conforme Smith et al. (2000), plantas daninhas que estãopresentes, mais tardias, nociclodoalgodoeiro, têmmenos influência na produtividade, sendo estas mais problemáticas na etapa da colheita do algodão. Esse comportamento entre os grupos de plantas daninhas pode estar ligado, não só ao ciclo das espécies, ou ao comportamento de outras populações de plantas, como também, ao próprio comportamento da cultura em relação à comunidade infestante, conforme salientam Pitelli e Pitelli (2008).

Os resultados de importância relativa (IR) (FIG. 2) assemelharam-se aos da dominância relativa, diferindo-se apenas pela população de capim-mimoso (ERAPI), tendo o seu máximo de importância aos 80 DAE (17,22\%). No entanto, observou-se que a população de maior importância, a Richardia grandiflora com 18,66\% e $24,56 \%$, respectivamente, aos 60 e 80 DAE, e jetirana (IPOPE) com 18,24\% aos 20 DAE, e permanecendo constante aos 60 e 80 DAE. 


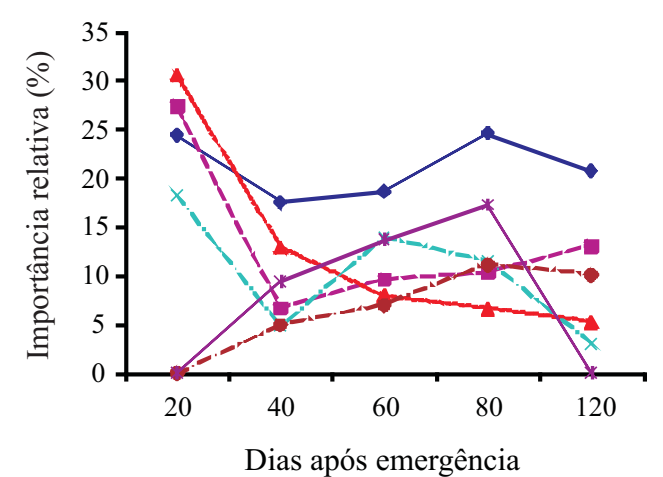

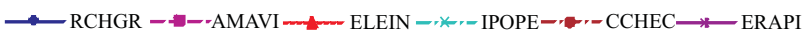

Figura 2 - Importância relativa (IR) das principais plantas daninhas presentes na área experimental em função do número de dias após emergência (DAE) do algodão de fibra naturalmente colorida. Missão Velha-CE 2007

Plantas do grupo das Liliopsidas prejudicam a produção, se conviverem com o algodão por um período de 10 e 20 dias. As Magnoliopsidas iniciam a redução na produção após sua permanência junto com a cultura por um período entre 20 e 30 dias, a contar da emergência do algodão (SALGADO et al., 2002). Verificou-se pelo acúmulo de fitomassa e pela importância relativa das populações da comunidade infestante, que os resultados observados no presente trabalho seguem um comportamento, o qual corrobora com informações dos pesquisadores supracitados.

Silva e Durigan (2006) salientam que, quanto maior a população da comunidade infestante, maior será a quantidade de indivíduos que disputam os recursos do meio e mais intensa será a competição com as culturas. Além disso, espécies morfológicas e fisiologicamente próximas apresentam exigências semelhantes aos recursos, tornando ainda mais intensa a competição.

Em relação aos períodos de competição, Christoffoleti et al. (2007) relatam que, em média, o período crítico de matocompetição das plantas daninhas no ciclo do algodoeiro herbáceo ocorre entre os 15 e 70 dias após a emergência das plantas de algodão, que é o intervalo de tempo no qual o controle de plantas daninhas deve ser realizado com objetivo de diminuir a competição inter-específica visando assegurar a produtividade. Na Tabela 3 são apresentados os parâmetros das equações obtidos na análise de regressão dos dados de produtividade para cultivar BRS Safira, em função dos períodos de interferência ou de controle das plantas daninhas. Observou-se bons valores dos coeficientes de determinação para equações, indicando bom ajuste da equação aos dados. Verifica-se também que os modelos encontrados foram significativos a $5 \%$ de probabilidade pelo teste $\mathrm{F}$.

Observa-se na Figura 3 as curvas de produtividade do algodão, ajustadas pelo modelo sigmoidal de Boltzmann, em função dos períodos de convivência ou de controle das plantas daninhas. Considerando-se perda de $2 \%$ na produtividade da cultura (FIG. $3 \mathrm{~A}$ ), verificou-se que a convivência com as plantas daninhas começou a afetar a cultura (período anterior a interferência - PAI) aos oito dias após a emergência, estendendo-se o controle até aos 108 dias após a emergência (período total de prevenção interferência - PTPI). O período crítico de prevenção à interferência (PCPI) se caracterizou pelo intervalo de oito a 108 dias após a emergência da cultura, totalizando 100 dias, nos quais a cultura não deve sofrer interferência das plantas daninhas.

Quando se considera uma perda de 5\% (FIG. 3B) observa-se que o PAI foi para 14 dias e o PTPI foi para 96 dias, determinando assim um período crítico de prevenção à interferência de 82 dias. Considerando-se uma perda de $10 \%$ na produtividade (FIG. $3 \mathrm{C}$ ), observa-se um PAI de 20 dias; PTPI de 80 dias, que gera um PCPI de 60 dias no algodão colorido (cultivar BRS Safira).

Estudando o período crítico de competição das plantas daninhas em algodoeiro irrigado usando a cultivar de ciclo curto, CNPA Precoce 1, Azevedo et al. (1994) verificaram que a presença das plantas daninhas nos primeiros 20 dias após a emergência das plântulas não reduziu a produtividade da cultura, quando comparado ao controle sem competição durante todo o ciclo da cultura, independente da largura das fileiras estudadas $(0,5 ; 0,8 \mathrm{e}$ $1,0 \mathrm{~m})$. Porém, o período crítico de competição variou em função do espaçamento entre as fileiras, sendo de 30 dias no espaçamento de $1,0 \mathrm{~m}$ entre fileiras com o PAI de 16 dias, 16 dias no espaçamento de $0,8 \mathrm{~m}$ (PAI de 18 dias) e 12 dias no espaçamento de $0,5 \mathrm{~m}$ entre as fileiras, com o PAI de 28 dias.

Tabela 3 - Parâmetros das equações sigmoidais de Boltzmann, ajustada aos dados de produção, em função dos períodos de convivência ou controle das plantas daninhas na cultura do algodão de fibra naturalmente colorida 'BRS Safira'. Missão Velha-CE, 2007

\begin{tabular}{cccc}
\hline & Equações & $\mathrm{R}^{2}$ & $\mathrm{~F}$ \\
\hline Convivência & $\hat{\mathrm{Y}}=146,32+\left\{(1780,40-146,32) /\left(1+\mathrm{e}^{[(\mathrm{X}-38,39) / 9,24]}\right)\right\}$ & 0,99 & $2080,76^{*}$ \\
\hline Controle & $\hat{\mathrm{Y}}=1820,80+\left\{(-49821,00-1820,80) /\left(1+\mathrm{e}^{[(\mathrm{X}-157,67) / 46,07]}\right)\right\}$ & 0,97 & $287,95^{*}$ \\
\hline
\end{tabular}

\footnotetext{
* significativo à $5 \%$ de probabilidade
} 

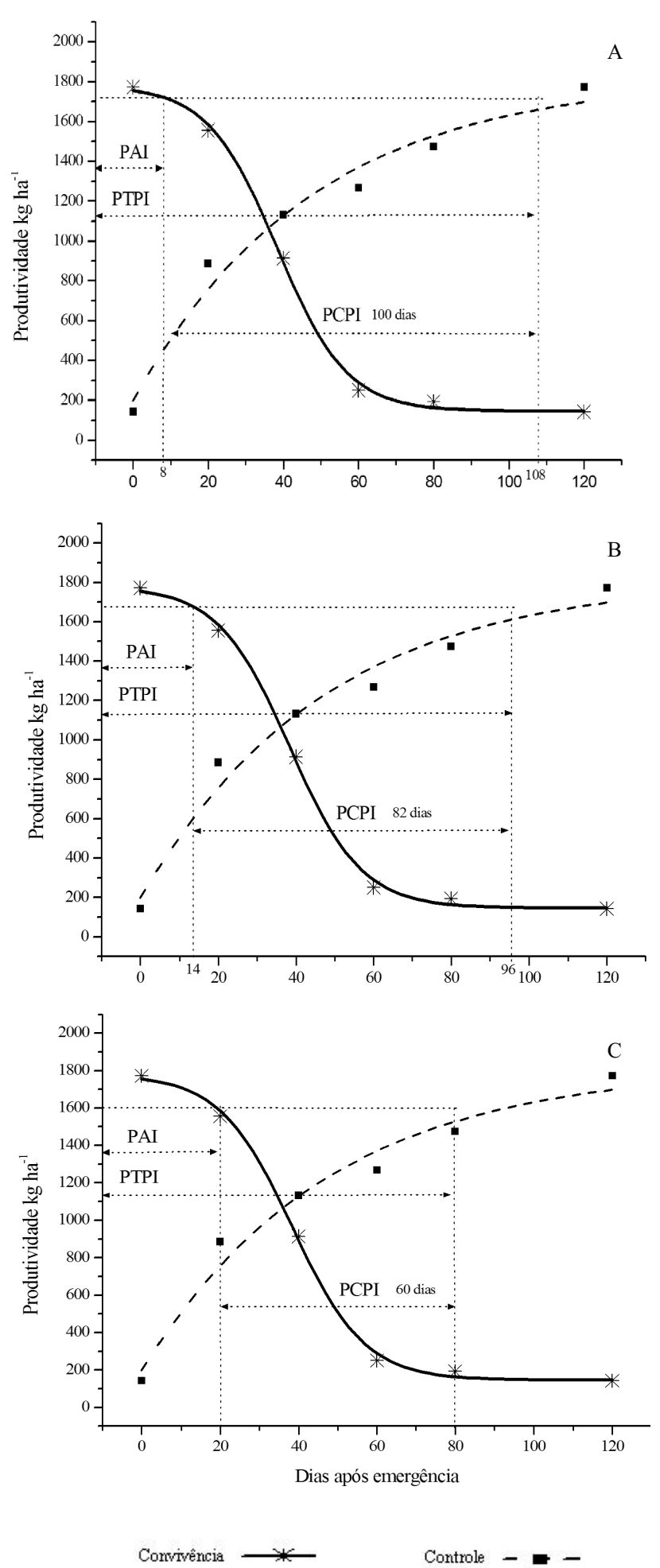

Figura 3 - Períodos de competição e ajuste dos dados pelo modelo sigmoidal de Boltzmann, em função dos períodos de controle e de convivência com as plantas daninhas, considerando-se perdas na produtividade de $2 \%$ (A); $5 \%$ (B) e $10 \%$ (C), 2007. Missão Velha-CE
Os resultados relatados por Azevedo et al. (1994) diferem dos obtidos no presente estudo. Porém, cabe salientar que o presente estudo foi conduzido em regime de sequeiro, em que se registraram poucas chuvas no ano de 2007, ressaltando que a precipitação pluvial é um dos fatores que proporciona variação da amplitude dos períodos de interferências numa mesma cultura, conforme salienta Beltrão (2004).

Estudando o período crítico na cultivar de algodão colorido semi-perene BRS 200, sob manejo orgânico, Silva (2003) determinou um período anterior à interferência de 38 dias após a semeadura e o período crítico de prevenção à interferência com uma duração de nove dias. Em um trabalho de períodos de competição de planta daninhas no algodão em dois anos, na Grécia, Papamichail et al. (2002) verificaram que já nas três primeiras semanas de competição houve perdas na produtividade de 8 e $13 \%$, respectivamente para os anos de 1997 e 1998. Os autores relatam que nos níveis aceitáveis de perdas na produtividade de 2 e $10 \%$, o período total de prevenção a interferência seria de 77 dias após a emergência; e o período crítico de prevenção a interferência nesses mesmos níveis de aceitação de perdas, teriam respectivamente, duração de 28 e 56 dias.

O algodoeiro por ter crescimento inicial lento, até os primeiros 20 dias após a emergência das plântulas, e apresentar metabolismo fotossintético $C_{3}$ de baixa eficiência transpiratória, é extremamente sensível ao estresse biótico causado pela interferência das plantas daninhas, exigindo muitas vezes que o controle seja realizado logo no início da cultura (BELTRÃO, 2004; BUKUN, 2004). Keeley e Thullen (1991), afirmam que a competição por luz no início do ciclo do algodão, é mais prejudicial ao algodoeiro, que a competição por água e nutrientes. Em espaçamentos mais largos como adotado no presente trabalho, a disponibilidade de luz e $\mathrm{CO}_{2}$ para as plantas daninhas é maior, e sua interferência sobre o algodoeiro é mais efetiva, sendo a luminosidade um dos fatores climáticos de maior importância para o crescimento, desenvolvimento e produção do algodoeiro, exercendo função básica sobre o potencial produtivo (AZEVEDO et al., 1994; SILVA et al., 2005). Esses aspectos, em conjunto com a ampla distribuição das plantas daninhas, tanto em número como em espécies, durante o ciclo da cultura, podem explicar a grande amplitude dos períodos de interferência observados (ERMAN et al., 2008).

\section{Conclusões}

1. Na comunidade infestante presente no algodoeiro de fibra colorida cultivar BRS Safira, na região do Cariri em 
Missão Velha, CE, as plantas do grupo das Liliopsidas têm maior importância no início do ciclo do algodoeiro, enquanto que as espécies das Magnoliopsidas têm comportamento, no que diz respeito à dominância relativa e importância relativa, mais constante durante todo ciclo do algodoeiro.

2. Os período críticos anterior a interferência, considerando perdas nas produtividades de 2; 5 e 10\%; são 8 ; 14 e 20 dias após a emergência do algodoeiro, e os períodos críticos de prevenção a interferência, para esses mesmos níveis de perdas, estão num intervalo de tempo, respectivamente, 8-108; 14-96 e 20-80 dias.

3. A ausência de controle das plantas daninhas causou um prejuízo de até $91,93 \%$ na produtividade do algodoeiro na região do Cariri em Missão Velha, CE.

\section{Referências}

AZEVEDO, D. M. P. de. et al. Período crítico de competição entre plantas daninhas e o algodoeiro anual irrigado. Pesquisa Agropecuária Brasileira. Brasília, v. 29, n. 09, p. 14141425, 1994.

BELTRÃO, N. E. de M. Manejo e controle de plantas daninhas em algodão. In: VARGAS, L.; ROMAN, E. S. (Ed.). Manual de manejo e controle de plantas daninhas. Sete Lagoas: Embrapa, 2004. cap.10, p.215-250.

BELtRÃO, N.E. de M.; CARVAlHO, L.P. de. Algodão colorido no Brasil, e em particular no Nordeste e no Estado da Paraíba. 2004. 18p. Campina Grande: Embrapa Algodão. (Documentos, 128).

BUKUN, B. Critical periods for weed control in cotton in Turkey. Weed Research, v. 44, n. 05, p. 404-412, 2004.

CHRISTOFFOLETI, P. J. et al. Manejo de plantas daninhas na cultura do algodão. In: FREIRE, E. C. (Ed.). Algodão no cerrado brasileiro. São Paulo: ABRAPA, 2007. cap. 14, p. 523-550.

ERMAN, M. Critical period of weed control in winter lentil under non-irrigated conditions in Turkey. African Journal of Agricultural Research, v. 03, n. 08, p. 523-530, 2008.

FREITAS, R. S. et al. Interferência de plantas daninhas na cultura do algodão em sistema de plantio direto. Planta Daninha, v. 20, n. 02, p. 197-205, 2002.

FREITAS, R. S. et al. Manejo de plantas daninhas na cultura do algodoeiro em sistema de plantio direto. Planta Daninha, v. 24, n. 02, p. 339-346, 2006.
KEELEY P. E.; THULLEN R. J. Growth and interaction of barnyardgrass (Echinochloa crus-galli) with cotton (Gossypium hirsutum). Weed Science, v. 39, n. 03, p. 369-375. 1991.

KNEZEVIC, S. Z. et al. Critical period for weed control: the concept and data analysis. Weed Science, v. 50, n. 06, p. 773-786, 2002.

KUVA, M. A. et al. Períodos de interferência das plantas daninhas na cultura da cana-de-açúcar. I - Tiririca. Planta Daninha, v. 18, n. 02 , p. $241-251,2000$

MELHORANÇA, A. L.; BELTRÃO, N. E. de M. Plantas daninhas: importância e controle. In: EMPRESA BRASILEIRA DE PESQUISA AGROPECUÁRIA (EMBRAPA). Centro de Pesquisa Agropecuária do Oeste. Algodão: informações técnicas. Dourados: Embrapa-CPAO/Embrapa-CNPA, 2001. cap 11. p. 227-237.

MORGAN G. D; BAUMANN, P. A.; CHANDLER, J. M. Competitive impact of palmer amaranth (Amaranthus palmeri) in cotton (Gossypium hirsutum) development and yield. Weed Technology, v. 15, n. 03, p.408-412, 2001

MUELLER-DOMBOIS, D.; ELLEMBERG, H. Aims and methods of vegetation ecology. New York: John Willey \& Sons, 1974. $547 \mathrm{p}$.

PAPAMICHAIL, D. I. et al. Critical Periods of Weed Competition in Cotton in Greece. Phytoparasitica, v. 30, n. 01, p. 105-111. 2002.

PITELLI, R. A.; PITELLI, R. L. de C. M. Biologia das plantas daninhas. In: VARGAS, L.; ROMAN, E. S. (Ed.). Manual de manejo e controle de plantas daninhas. Bento Gonçalves: Embrapa Uva e Vinho, 2008. cap.1, p.11-38.

SALGADO, T. P. et al. Períodos de interferência das plantas daninhas na cultura do algodoeiro (gossypium hirsutum). Planta Daninha, v. 20, n. 03, p. 373-379, 2002.

SILVA, M. N. B. da. Manejo cultural do algodoeiro colorido BRS 200 em cultivo orgânico no Semi-Árido Paraibano. 2003, 114 f. Tese (Doutorado em Agronomia) - Universidade Federal da Paraíba, Areia.

SILVA, A. F. da et al. Interceptação da luz, matéria seca e área foliar de linhagens de algodoeiro herbáceo. Revista Ciência Agronômica, v. 36, n. 01, p. 67-73, 2005.

SILVA, M. R. M.; DURIGAN, J. C. Períodos de interferência das plantas daninhas na cultura do arroz de terras altas. I cultivar IAC 202. Planta Daninha, v. 24, n. 04, p. 685-694, 2006.

SMITH, D. T.; BAKER, R. V.; STEEL, G. L. Palmer Amaranth (Amaranthus palmeri) impacts on yield, harvesting, and ginning in dry land cotton (Gossypium hirsutum). Weed Technology, v. 14, n. 01, p. 122-126, 2000. 